\title{
Sensorimotor control in Parkinsonism ${ }^{1}$
}

\author{
DAVID J. DE L. HORNE \\ From the Department of Psychiatry, University of Melbourne, \\ Victoria 3052, Australia
}

SUMMARY Performance on two sensorimotor tasks was compared between 28 patients with Parkinsonism and 28 age and sex matched controls. One task involved complex motor activity (the Bead and Tapper test) and the other simple motor activity with a verbal component (the Letter Cancellation test). Both tests had three levels of complexity. Under conditions of increasing complexity in the performance required, the scores for the Parkinsonism subjects decreased disproportionately compared with the controls. This finding was more clearly established for the Bead and Tapper test than for the Letter Cancellation test. These results confirmed previous studies, and the nature of a possible central programming deficit was discussed. Laterality of brain involvement in the Parkinsonism subjects had no significant effect.

It now appears proven that patients with Parkinsonism have, in addition to the welldocumented motor symptoms, some sensorimotor difficulties that cannot be attributed to purely motor dysfunction. Some investigations into the nature of this central deficit occurring with damage to the basal ganglia have taken the form of testing the ability to make judgements about spatial orientation on the basis of interactions between body posture and distance receptors (Teuber and Proctor, 1964). Other studies have tested the ability of patients with Parkinsonism to carry out various sensorimotor tasks involving manual skills (Talland and Schwab, 1964; Perret et al., 1970) and, in one case, visual discrimination mediated by a verbal motor response (Horne, 1971). In general, these latter type of studies have shown that increased task complexity produced a disproportional decrement in the performance of patients with Parkinsonism, thus providing evidence of a central processing deficit.

One of the earliest, well-controlled, experiments to investigate sensorimotor deficits in the Parkinsonism syndrome was that by Talland and Schwab (1964). They used two series of tasks each having different levels of complexity. One

1 This work was carried out in part fulfilment of the requirement for a PhD degree, University of Melbourne. required the subject to move beads with a pair of tweezers and to tap a counter, both unimanually and bimanually, and the other involved cancelling $\mathbb{R}$ printed letters according to three different sets of instructions. It was found that the patients with Parkinsonism performed disproportionatelye badly under the bimanual condition of the beado and counter task, and that,

'The difficulty the Parkinsonian patients encountered in the cancellation test was not in manual dexterity, but in executing a plan with alternative possibilities' (Talland and Schwab, 1964, p. 51).

The study reported below aimed at replicating this work in as much detail as possible to extend the generality of the results. In addition, the effects of laterality of brain pathology were considered in order to help increase understanding of the nature of the role of subcortical centres in mediating higher functions.

It has been shown that generally, in Parkinsonism, damage to

... the left hemisphere produces a bimanual deficit in tasks requiring repetitive movements of the arm, manual dexterity, or precision. In contrast, the right hemisphere produces a singular contralateral effect on the left hand' (Proctor Bowen et al., 1972).

Since subjects were not tested separately on each hand in either the original study (Talland and Schwab, 1964) or in the current study, the 
findings on brain pathology laterality must be limited. However, an important parameter differentiating the two tasks is the verbal factor involved in the Letter Cancellation tests.

It was postulated that lateralization of verbal function would not extend to the basal ganglia, so that there should be no difference between the performance of Parkinsonism patients with primarily left or right brain pathology on the Letter Cancellation tests. Although both hands were not tested separately in the Bead and Tapper experiment, the assumption was that, since both hands were involved in the bimanual condition, those patients with left brain pathology would do worse.

\section{METHOD}

SUBJECTS There were 28 patients with Parkinsonism, none of whom had had brain surgery or treatment by L-dopa. Fifteen were male and 13 were female, and their mean age was 58.5 years $(\mathrm{SD}=9.8)$. Two were left handed (one male and one female). All were able to do the Bead and Tapping test, but three of the males could not cope with the Letter Cancellation tests because of language difficulties and illiteracy.

Laterality of brain pathology was determined from recorded motor symptoms. Fourteen subjects had left brain pathology (nine male and five female); 11 had right brain pathology (four male and seven female); and three had bilateral involvement (one male and two female).

CONTROL SUBJECTS Fifteen male and 13 female subjects with no brain damage or physical handicap were chosen from patients who had been in hospital for observation and were about to be discharged (12 subjects), and from the academic and hospital staff (16 subjects). The mean age of the group was 58.9 years $(S D=10 \cdot 1)$. Two were left handed (one male and one female). There was no significant difference in age between the experimental and control subjects $(t=0 \cdot 15)$.

BEAD AND TAPPER TEST This test was closely modelled on that described by Talland and Schwab (1964).

The apparatus consisted of:

1. A wooden baseboard with two recesses, centres $15.5 \mathrm{~cm}$ apart, containing two clear plastic cups. The cups had a mouth diameter of $7 \cdot 3 \mathrm{~cm}$ and a depth of $6 \cdot 7 \mathrm{~cm}$.
2. Wooden beads: 100 blue; 50 brown; 50 white. All were $7.15 \mathrm{~mm}$ in diameter. The beads were placed in the cups in varying ways for different trials.

3. One pair of fine pointed tweezers, $12.8 \mathrm{~cm}$ long, for transferring the beads from one cup to another.

4. One morse-tapping instrument, set for hand travel of $0.5 \mathrm{~cm}$.

5. A Sodeco $12 \mathrm{~V}$ d.c. impulse counter, model TCeZ3E for recording the number of taps made.

PROCEDURE The subject was seated comfortably in front of a table containing the apparatus. The baseboard containing the cups was placed so that the left hand cup was in the subject's midline. The right hand cup contained the beads to be moved with tweezers. For the four left handed subjects the right hand cup was in the subject's midline and the left hand cup contained the beads. A standardized procedure of using the tweezers and tapping the morse tapper was demonstrated by the experimenter before the subject had a practice session of about 30 seconds at both components of the test.

The instructions, nature, and order of the trials were standardized. The details of these are available from the author. In summary, there were ten trials of 60 seconds each for varying combinations of bead and tapper, which are tabulated below.

\section{TABLE 1}

ORDER AND NATURE OF TRIALS IN THE BEAD AND TAPPER TEST

\begin{tabular}{cll}
\hline $\begin{array}{c}\text { Sequential order of } \\
60 \text { sec trials }\end{array}$ & \multicolumn{1}{c}{ Nature of trial } & Hand used \\
\hline 1 and 10 & $\begin{array}{l}\text { Beads of single colour } \\
\text { (blue) } \\
\text { Tapper alone }\end{array}$ & Preferred (right) \\
$\mathbf{3}$ and 8 & $\begin{array}{l}\text { Tapper and blue beads } 9 \\
\text { Beads selected for colour } \\
\text { (brown) }\end{array}$ & $\begin{array}{l}\text { Non-preferred } \\
\text { (left) } \\
\text { Both } \\
\text { Preferred (right) }\end{array}$ \\
5 and 7 & $\begin{array}{c}\text { Tapper and brown beads } \\
\text { Bath }\end{array}$ & Both \\
\hline
\end{tabular}

In trials $4,6,5$, and 7 , the subject was required to select only the brown beads from the mixture of brown and white beads, and transfer them to the empty cup.

SCORING Scores used were the number of beads successfully transferred to the empty cup, and number of taps made. Average scores for each set of two 60 second trials are reported in the results.

In addition, ratios of mean level of performance under the bimanual conditions were calculated by 
TABLE 2

MEAN AND SD SCORES ON THE BEAD AND TAPPER TEST

\begin{tabular}{|c|c|c|c|c|c|c|c|c|}
\hline & & \multicolumn{3}{|c|}{ Tapper } & \multicolumn{2}{|c|}{ Blue beads } & \multicolumn{2}{|c|}{ Brown beads } \\
\hline & & Alone & $\begin{array}{c}\text { With blue } \\
\text { beads }\end{array}$ & $\begin{array}{l}\text { With brown } \\
\text { beads }\end{array}$ & Alone & With tapper & Alone & With tapper \\
\hline $\begin{array}{l}\begin{array}{l}\text { Control } \\
(\mathrm{n}=28)\end{array} \\
\text { Parkinsonism } \\
(\mathrm{n}=28) \\
t \text { test } \\
\mathrm{P}\end{array}$ & $\begin{array}{r}\bar{x} \\
S D \\
\bar{x} \\
S D\end{array}$ & $\begin{array}{c}308.7 \\
61.6 \\
221.5 \\
75.4 \\
4.74 \\
<0.001\end{array}$ & $\begin{array}{c}213 \cdot 7 \\
61 \cdot 1 \\
124 \cdot 2 \\
78 \cdot 7 \\
4 \cdot 75 \\
<0.001\end{array}$ & $\begin{array}{c}197 \cdot 7 \\
68 \cdot 8 \\
112 \cdot 3 \\
76 \cdot 1 \\
4 \cdot 41 \\
<0 \cdot 001\end{array}$ & $\begin{array}{c}30 \cdot 5 \\
8 \cdot 8 \\
15 \cdot 7 \\
7 \cdot 6 \\
6 \cdot 74 \\
<0.001\end{array}$ & $\begin{array}{c}27 \cdot 2 \\
8.7 \\
12 \cdot 4 \\
6 \cdot 7 \\
7 \cdot 13 \\
<0.001\end{array}$ & $\begin{array}{c}25 \cdot 2 \\
7 \cdot 3 \\
14 \cdot 3 \\
7 \cdot 3 \\
5 \cdot 59 \\
<0 \cdot 001\end{array}$ & $\begin{array}{c}22 \cdot 9 \\
7 \cdot 1 \\
10 \cdot 4 \\
6 \cdot 6 \\
6 \cdot 83 \\
<0.001\end{array}$ \\
\hline
\end{tabular}

All scores are derived from the mean of two $60 \mathrm{sec}$ trials.

dividing the scores for tapping unimanually by scores for tapping while transferring beads with tweezers and, similarly, for transferring beads while tapping.

LETTER CANCELliNG TEST Again, this test was modelled on that reported by Talland and Schwab (1964). There were three tests of increasing complexity and each was performed over two 60 second trials. A fresh page of letters was used for each trial. Each page consisted of rows of typed letters, constructed as follows: (1) each page had four sections of four lines; (2) each line had 10 capital and 26 lower case letters arranged randomly and separated by single spaces, except for four randomly allocated double spaces.

PROCEDURE In summary, this was, for each test, as follows:

Test $A$ (most simple) Crossing out only the capital letters.

Test $B$ (presumed next most complex) Crossing out capital letters and any letter, whether upper or lower case, that immediately followed a double space.
TABLE 3

MEAN LEVEL OF WORK UNDER BIMANUAL PERFORMANCE

\begin{tabular}{|c|c|c|c|c|c|}
\hline & & \multicolumn{2}{|c|}{ Tapper with } & \multirow{2}{*}{$\begin{array}{c}\text { Blue } \\
\text { beads }\end{array}$} & \multirow{2}{*}{$\begin{array}{l}\text { Brown } \\
\text { beads }\end{array}$} \\
\hline & & \multirow{2}{*}{$\begin{array}{c}\text { Blue } \\
\text { beads }\end{array}$} & \multirow{2}{*}{$\begin{array}{l}\text { Brown } \\
\text { beads }\end{array}$} & & \\
\hline & & & & \multicolumn{2}{|c|}{ with Tapper } \\
\hline \multirow{6}{*}{$\begin{array}{l}\text { Control } \\
(\mathrm{n}=28) \\
\text { Parkinsonism } \\
(\mathrm{n}=28) \\
t \text { test } \\
\mathrm{P}\end{array}$} & $\overline{\mathbf{x}}$ & 0.69 & 0.64 & 0.90 & 0.91 \\
\hline & SD & $0 \cdot 13$ & $0 \cdot 16$ & $0 \cdot 17$ & 0.13 \\
\hline & $\overline{\mathrm{x}}$ & 0.53 & 0.48 & 0.77 & $0.7 \mathrm{E}$ \\
\hline & SD & 0.21 & 0.22 & $0 \cdot 24$ & 0.27 \\
\hline & & 3.43 & $3 \cdot 12$ & $2 \cdot 34$ & $3 \cdot 54$ \\
\hline & & $<0.01$ & $<0.01$ & $<0.05$ & $<0.0$ \\
\hline
\end{tabular}

Test $C$ (presumed most complex) Crossing ou capital letters and all letters that immediatel preceded and followed double space.

Further details of the procedure are available from the author.

SCORING As in the 1964 study, scores were based on: (a) total letters correctly cancelled, (b) errors by omission, (c) errors by incorrect cancellation, and

TABLE 4

MEAN AND SD SCORES ON THE LETTER CANCELLATION TEST

\begin{tabular}{|c|c|c|c|c|c|c|c|c|c|}
\hline & \multicolumn{3}{|c|}{$\begin{array}{c}\text { Correct cancellation } \\
\text { per } 60 \mathrm{sec}\end{array}$} & \multicolumn{3}{|c|}{ Error ratio } & \multicolumn{3}{|c|}{ Omission ratio } \\
\hline & $A$ & $B$ & $C$ & $A$ & $B$ & $C$ & $A$ & $B$ & C \\
\hline $\begin{array}{lr}\text { Control } & \overline{\mathrm{x}} \\
\mathrm{n}=28 & \mathrm{SD} \\
\text { Parkinsonism } & \overline{\mathrm{x}} \\
\mathrm{n}=25 & \text { SD } \\
& t \text { test } \\
& \mathrm{P}\end{array}$ & $\begin{array}{c}44 \cdot 0 \\
16 \cdot 6 \\
26 \cdot 3 \\
13 \cdot 0 \\
4 \cdot 29 \\
<0 \cdot 001\end{array}$ & $\begin{array}{c}40 \cdot 5 \\
15 \cdot 5 \\
26 \cdot 1 \\
11 \cdot 7 \\
3 \cdot 78 \\
<0 \cdot 001\end{array}$ & $\begin{array}{c}47 \cdot 2 \\
19 \cdot 2 \\
29 \cdot 9 \\
12 \cdot 5 \\
3.84 \\
<0 \cdot 001\end{array}$ & $\begin{array}{r}0.16 \\
0.21 \\
0.29 \\
0.26 \\
2.02 \\
<0.05\end{array}$ & $\begin{array}{r}0.21 \\
0.21 \\
0.37 \\
0 \cdot 36 \\
2.01 \\
<0.05\end{array}$ & $\begin{array}{l}0 \cdot 18 \\
0 \cdot 19 \\
0 \cdot 29 \\
0 \cdot 22 \\
1.96 \\
\text { NS }\end{array}$ & $\begin{array}{r}0.02 \\
0.03 \\
0.04 \\
0.03 \\
2.44 \\
<0.05\end{array}$ & $\begin{array}{r}0.04 \\
0.03 \\
0.07 \\
0.05 \\
2.73 \\
<0.01\end{array}$ & $\begin{array}{l}0.05 \\
0.04 \\
0.08 \\
0.09 \\
1.61 \\
\text { NS }\end{array}$ \\
\hline
\end{tabular}

All scores are derived from the mean of two $60 \mathrm{sec}$ trials. 
(d) number of letters between the starting point and the last cancellation mark. Actual scores included only (a) in its raw form; additional scores were compounded from ratios of (b plus c) to (a), the error score; and of (b) to (d) the omission score (Talland and Schwab, 1964, pp. 47/8).

\section{RESULTS}

BEAD AND TAPPER TEST The mean and standard deviation scores for the Parkinsonism and control groups are shown in Tables 2 and 3 .

From these Tables it can be seen that on all scores the Parkinsonism subjects performed worse than the controls. Results were compared between the Parkinsonism subjects with left and right major brain pathology and no significant differences were found.

LETTER CANCELLATION TEST Mean and standard deviation scores for the Parkinsonism and control groups are presented in Table 4.

The results in this Table show that the Parkinsonism group had a significantly lower mean number of correct cancellations per 60 second trial. Both the Error ratio scores and the Omission ratio scores were significantly different on tasks A and B, but not on task C.

There were no significant differences between the left and right brain pathology groups of Parkinsonism subjects.

\section{DISCUSSION}

The aim of replicating the findings of the two experiments reported by Talland and Schwab (1964) was successful to a large extent. The only difference in performance on the Bead and Tapper test in the present experiment compared with the earlier study was that under bimanual performance (see Table 3 ) the bead scores were significantly different for the Parkinsonism and control groups, whereas in the earlier study there was no significant difference. Thus, in the present experiment, both motor components of the test were significantly affected by having to perform them simultaneously.

A possible reason for this difference could be that the present task, although closely modelled on that by Talland and Schwab (1964), was in fact more difficult and taxed the subjects with
Parkinsonism to their limit. However, the actual mean scores in Table 3 for the controls are virtually identical with those for Talland and Schwab's control group (1964, p. 48), while those for the Parkinsonism group are lower. Another factor, therefore, may be that the present Parkinsonism subjects were more severely impaired, and there is some confirmation for this because the mean scores for the Parkinsonism group in Table 2 are very similar to those for Talland and Schwab's (1964, p. 48) severely disabled group. Severity of impairment was not treated separately here because of the relatively small numbers of subjects and the difficulty in defining 'severity' in a satisfactory way. If patients were so severely handicapped that they could not complete the test their scores were excluded from the analysis. Another difference between the present study and the earlier one is the design of the tapping instrument. The absolute number of taps made were consistently higher in the present experiment, but the pattern of performance exactly mirrored that of Talland and Schwab's (1964) study.

Thus, there is weighty evidence that having to perform two motor tasks simultaneously does worsen the level of performance in Parkinsonism patients more than in controls. The Bead and Tapper test used appears to be a very reliable means of assessing this deficit. Some additional evidence for its reliability comes from a study by Gill (1972) who tested a group of depressed patients before and after treatment and a group of matched controls. These two groups did not differ in age from the Parkinsonism and control group of the present study. Of relevance here is that his control group had very similar scores to the present control group on this test; the depressed group before treatment scored midway between both sets of normals and the Parkinsonism group, and improved significantly after treatment.

The second test used by Talland and Schwab (1964) was designed to test whether the deficit seen with motor functions was purely one of a reduction in capacity for executing two tasks simultaneously, or whether an inability to shift in set from complying with one set of instructions to another was also involved. Their finding that, on the Letter Cancellation test, the Parkinsonism group were not poorer on test $\mathrm{A}$, but were on 
tests $\mathrm{B}$ and $\mathrm{C}$ was interpreted as indicating primarily a deficit in central programming rather than 'a difference in motor capacity or in perceptual processing' (ibid. p. 51). However, the present results showed a difference between the Parkinsonism and control groups on the 'correct cancellation' score for all three tests, and also on both the error and omission ratio scores for tasks A and B (Table 4). This would not contradict Talland and Schwab's (1964) contention that a central programming defect is involved, but does also suggest that the whole task was very much harder for the Parkinsonism group, possibly from the point of view of both central programming and of motor coordination.

From subjective impressions gained during the research, this test appeared to be much more anxiety provoking and stressful than the Bead and Tapper test and subjects, particularly the Parkinsonism patients, sometimes became confused about what was supposed to be done on each trial, even though this had been repeated to them a few seconds previously. This inability to grasp the instructions could reflect a central programming defect but could equally reflect a high level of anxiety, possibly associated with an often-present difficulty in writing. This test appeared much less reliable than the Bead and Tapper test.

The effect of laterality of major brain pathology on these two tests was investigated among the Parkinsonism group. In these analyses of results the data for the two left-handed patients (both with left brain pathology) were excluded. The finding of no significant differences between these two subgroups is evidence that for performing complex motor tasks, as in the case of at least the Bead and Tapper test, there is no laterality effect. This is in contradistinction to the finding for simple, repetitive, motor manual tasks, where left brain damage has been found to produce bilateral deficits and right brain damage only a contralateral deficit. This could be because more central programming is required for the complex 0

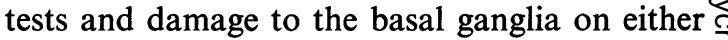
side can produce a deficit in this function.

At the beginning of the experiment it was? postulated that left subcortical damage might $\overrightarrow{\vec{F}}$ produce a greater deficit in performance on the task involving verbal function, the Letter Cancellation task, than right brain damage. That this did not happen could be interpreted as $\underset{\Omega}{\mathbb{Q}}$ further evidence for the bilateral distribution of a possible central programming mechanism but it ${ }^{\mathrm{s}}$

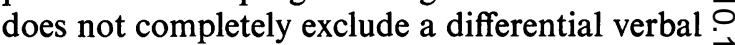
effect because cancelling letters may be more of a $\vec{\omega}$ spatial and form perceptual task than a verbal one. This needs to be tested further using more complex verbal tasks that also involve a significant motor component.

\section{REFERENCES}

Gill, J. (1972). Psychomotor, perceptual and physiologica testing in depressive illness. Unpublished B. Med. Sciी thesis. University of Melbourne, Australia.

Horne, D. J. de L. (1971). Performance on delayed response tasks by patients with Parkinsonism. Journal of Neurologe Neurosurgery, and Psychiatry, 34, 192-194.

Perret, E., Eggenberger, E., and Siegfried, J. (1970). Simpere and complex finger movement performance of patients with Parkinsonism before and after a unilateral stereotaxic $\omega$ thalamotomy. Journal of Neurology, Neurosurgery, and $\square$ Psychiatry, 33, 16-21.

Proctor Bowen, F., Hoehn, M. M., and Yahr, M. D. (1972) Cerebral dominance in relation to tracking and tapping performance in patients with parkinsonism. Neurology, (Minneap.) 22, 32-39.

Talland, G. A., and Schwab, R. S. (1964). Performance with multiple sets in Parkinson's disease. Neuropsychologia, 2, 45-53.

Teuber, H.-L., and Proctor, F. (1964). Some effects of basal ganglia lesions in subhuman primates and man. Neuropsychologia, 2, 85-93. 